\title{
Narrow and wide India-Burma trough-like circulations: their different impacts on precipitation over southern China
}

\author{
Jing-Xin Li ${ }^{1}$, Ge Liu ${ }^{1,2^{*}} \mathbb{D}$, Renguang Wu ${ }^{3}$, Hong-Li Ren ${ }^{1 *}$, Hui-Mei Wang ${ }^{1}$, Xin Mao and Xin-Chen Wei ${ }^{1}$
}

\begin{abstract}
The India-Burma troughs (IBTs) with different shapes (i.e., narrow and wide IBT-like circulations) can significantly affect winter precipitation over different regions in southern China through modulating the paths of water vapor transportation ahead of the IBTs. The effect of the wide/narrow IBT- (WIBT/NIBT-) like circulation cannot be depicted by traditional IBT indices that mainly focus on the IBT's intensity. This study defines the WIBT and NIBT indices, which can effectively distinguish different water vapor transportation in front of the WIBT and NIBT and relevant water vapor convergence and therefore successfully reflect different distributions of winter precipitation anomalies over southern China. Further exploration reveals that a Rossby wave from the Mediterranean Sea to the Bay of Bengal (BoB) contributes to the variability of the NIBT, while the El Niño-Southern Oscillation (ENSO) can modulate the variability of the WIBT by stimulating the Matsuno-Gill response. The WIBT and NIBT indices should be considered as important supplements to the traditional IBT indices, which are favorable to more detailed diagnosis and prediction of winter climate over southern China.
\end{abstract}

Keywords: India-Burma trough, Winter precipitation, Southern China, ENSO, Rossby wave

\section{Introduction}

Over the Asian subtropics, the tropospheric westerlies split into two branches along the north and south of the Tibetan Plateau (Fig. 1). Along the south branch, a dynamic trough forms over the Bay of Bengal (BoB), which is often called the India-Burma trough (IBT) (Yang et al. 1960; Suo and Ding 2009). The IBT, which is a semi-permanent atmospheric circulation system during the boreal winter half year, has great influences on weather and climate over South and East Asia (Dao 1953; Wang et al. 2011; Nan and Zhao 2012; Lü et al. 2012; Lu and Ren 2016; Liu et al. 2018; Li and Huang 2020).

*Correspondence: liuge@cma.gov.cn; renhl@cma.gov.cn

1 State Key Laboratory of Severe Weather, Chinese Academy of Meteorological Sciences, 46 Zhong-Guan-Cun South Avenue, Beijing 100081, China

Full list of author information is available at the end of the article
In front of the IBT, the southwesterly winds transport warm and moist air from the BoB to Southwest China and supply abundant water vapor to winter precipitation there (Li and Zhou 2015). The water vapor transported by the IBT determines, to a large extent, the intensity of the trough-induced precipitation (Zhang et al. 2007; Duan et al. 2012). For example, a deeper-than-normal (i.e., stronger) IBT induced water vapor transportation to Southwest China and caused a heavy snowstorm there during the winter of 2007 (Suo and Ding 2014). However, during December 2013, a strengthened IBT transported moisture from the BoB and the South China Sea to southern China and resulted in extreme heavy rainfall over Southeast China ( $\mathrm{Li}$ and Sun 2015). The above two cases illustrate that precipitation anomalies may occur in different regions corresponding to different paths of water vapor induced by an intensified IBT.

Several indices have been defined to measure the intensity of the IBT on interannual-decadal timescales based 


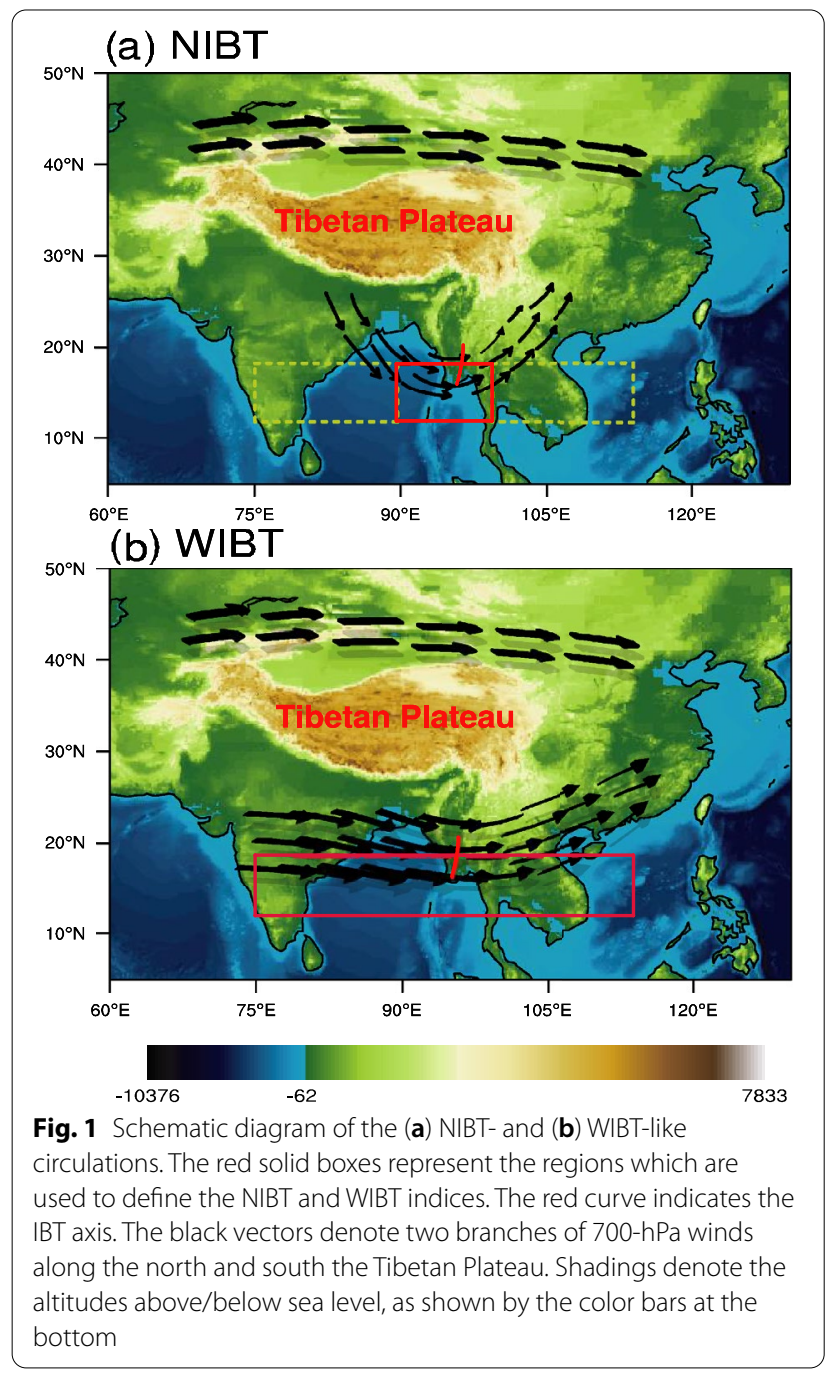

on area-mean 700-hPa vorticity (Wang et al. 2011; Lu and Ren 2016) and 500/700-hPa geopotential height (Zhang et al. 2007, 2012; Duan et al. 2012) around the BoB. These traditional IBT indices are generally related to winter precipitation over southern China, but do not clearly distinguish different paths of water vapor transportation induced by the IBT and associated precipitation anomalies over different regions of southern China. Thus, new indices are needed to capture the differential modulation of the IBT on the path of transportation of water vapor.

According to previous studies (Zhang et al. 2007, 2012; Wang et al. 2011; Duan et al. 2012; Suo and Ding 2014; Li and Sun 2015; Li and Zhou 2015; Lu and Ren 2016; Li et al. 2017), the intensity of the IBT does not seem to be the only factor influencing the distribution of precipitation anomalies over southern China. The shape of the IBT-related circulation also plays an important part in modulating winter precipitation over southern China.
The path of transportation of water vapor seems to be mainly attributed to the shape (narrow or wide) of the IBT. When a narrow IBT-like circulation appears, the airflows in front of this trough rapidly turn northeastward and accordingly water vapor is transported to Southwest China (Li et al. 2007; You et al. 2011; Duan et al. 2012; Nan and Zhao, 2012). In contrast, when a widened IBTlike circulation appears, the airflows in front of this trough continually move eastwards and gradually turn northeastward around the South China Sea, transporting water vapor to Southeast China (Zong et al. 2012; Li and Sun 2015). Consequently, the location of precipitation may differ depending upon the shape of the IBT.

Some previous studies reveal the potential factors affecting the variability of the IBT. The upstream African and Asian subtropical jet and Rossby wave propagation along this jet play an important role in modulating the IBT (Yin, 2005), in which the North Atlantic Oscillation seems to trigger this upstream circulation pattern (Zong et al. 2012). The El Niño-Southern Oscillation (ENSO) can affect the activity of the IBT through modulating the South Asian jet wave train (Li and Zhou, 2015). The warmer sea surface temperatures (SSTs) in the tropical Indian Ocean contribute to the deepening of the IBT (Yang et al. 2004; Lu and Ren 2016). The variability of the heat source over the Tibetan Plateau can also affect the intensity of the IBT through adjusting the location of the subtropical jet (Rong et al. 2020). Additionally, the Madden-Julian oscillation can modulate the evolution of the IBT on intraseasonal timescales (Jia et al. 2011). These studies mainly focus on the factors that affect the intensity of the IBT, but do not distinguish the respective factors affecting the wide and narrow IBT-like circulations.

Obviously, the shape of the IBT cannot be described by the traditional IBT indices. As such, we attempt to define new IBT indices to reflect the wide/narrow IBT-like circulation. Additionally, the potential factors affecting the wide and narrow IBTs are explored, respectively. The new IBT indices may help further understand the impact of the IBT on winter precipitation, which is also conducive to the improvement in the prediction skill of winter precipitation over southern China.

\section{Data, methods, and definition of IBT indices Data}

The monthly precipitation at 160 observational stations over China, obtained from the National Meteorological Information Center (NMIC), China Meteorological Administration (CMA), was used. We also used monthly mean precipitation on $2.5^{\circ} \times 2.5^{\circ}$ grids from the Climate Prediction Center (CPC) Merged Analysis of Prediction (CMAP) (Xie and Arkin $1997)$ to confirm results. The monthly geopotential 
height, $\mathrm{U}$ - and $\mathrm{V}$-winds, and vertical velocity (omega) on $1.5^{\circ} \times 1.5^{\circ}$ grids were obtained from the ERAinterim of the European Centre for Medium-Range Weather Forecasts (ECMWF) (Dee et al. 2011). The monthly geopotential heights and $\mathrm{U}$ - and $\mathrm{V}$-winds on $2.5^{\circ} \times 2.5^{\circ}$ grids from the National Centers for Environmental Protection-National Center for Atmospheric Research (NCEP-NCAR) Reanalysis Product (Kalnay and Coauthors 1996) were also employed to evaluate the robustness of results. We used the National Oceanic and Atmospheric Administration (NOAA) extended reconstructed SST version 4 (Huang et al. 2015). The above SST data are on $2^{\circ} \times 2^{\circ}$ grids. The Niño 3.4 index was obtained from the NOAA CPC. The Niño 3.4 index is defined by the area-mean SSTA averaged in the tropical central and eastern Pacific (TCEP; $5^{\circ} \mathrm{S}-5^{\circ} \mathrm{N}, 170-120^{\circ} \mathrm{W}$ ). The above data are all extracted from 1979 to 2019 . The winter in this study is December, January, and February.

\section{Methods}

A linear fitting method was applied to extract the independent variability of one variable after removing the part of variation related to the other variable (Hu et al. 2012). For the two time series $X_{1}$ and $X_{2}$, the $\mathrm{X}_{2}$-related variation (called $\mathrm{X}_{1}{ }^{\prime}$ ) of $\mathrm{X}_{1}$ can be obtained through the linear fitting method, in which the variation $X_{1}$ is regarded as a dependent variable and the variation $\mathrm{X}_{2}$ as an independent variable. The residual of the linear fitting (i.e., the difference $\mathrm{X}_{1}$ minus $\mathrm{X}_{1}{ }^{\prime}$ ) is used to reflect the variation of $X_{1}$ independent of $X_{2}$ (Yue et al. 2020).

Correlation, composite and regression analyses were used in this study. Unless otherwise stated, the
Student's t-test was used to evaluate the statistical significance of these analyses.

\section{Definition of new IBT indices}

As Fig. 1 indicates, the westerly flow exists along the southern flank of the India-Burma trough (IBT), which should be considered as a part of the IBT. There is a close correspondence between the extent of zonal extension of the westerly flow and the shape of the IBT. Specifically, when the IBT is narrow, there is a sharp turn of winds from the northwesterly to the southwesterly around the IBT (Fig. 1a). As a result, the westerly flow along the southern flank of the IBT only covers a narrow region around the BoB (Fig. 1a). The variability of the westerly over this narrow region is independent of the westerly over the adjacent upstream and downstream regions, showing the discontinuity of the westerly flow. Thus, the NIBT index can be defined by area-mean $700-\mathrm{hPa}$ $\mathrm{U}$-winds averaged over this narrow region $\left(12-18{ }^{\circ} \mathrm{N}\right.$, $90-100{ }^{\circ} \mathrm{E}$; see Fig. 1a) after removing the variability of area-mean U-winds averaged over the upstream (12-18 $\left.{ }^{\circ} \mathrm{N}, 75-90{ }^{\circ} \mathrm{E}\right)$ and downstream $\left(12-18{ }^{\circ} \mathrm{N}, 100-115^{\circ} \mathrm{E}\right)$ regions through a linear fitting method (Hu et al. 2012; Yue et al. 2020). The anomalous $700-\mathrm{hPa}$ winds regressed upon the NIBT index show a NIBT-like circulation around the BoB (Fig. 2a).

The wide IBT (WIBT) index can be defined by areamean $700-\mathrm{hPa} \mathrm{U}$-winds averaged over this wide region $\left(12-18{ }^{\circ} \mathrm{N}, 75-115^{\circ} \mathrm{E}\right.$; see Fig. 1b). The WIBT index represents the intensity of the westerly from India to the South China Sea, showing a wide spread of westerly anomaly. The anomalous $700-\mathrm{hPa}$ winds regressed upon the WIBT index shows that the westerly flow gradually turns northeastward to southern China via the Indochina continent (Fig. 2b). This turn seems to be linked with, at least partly, the IBT. The result indicates that the WIBT

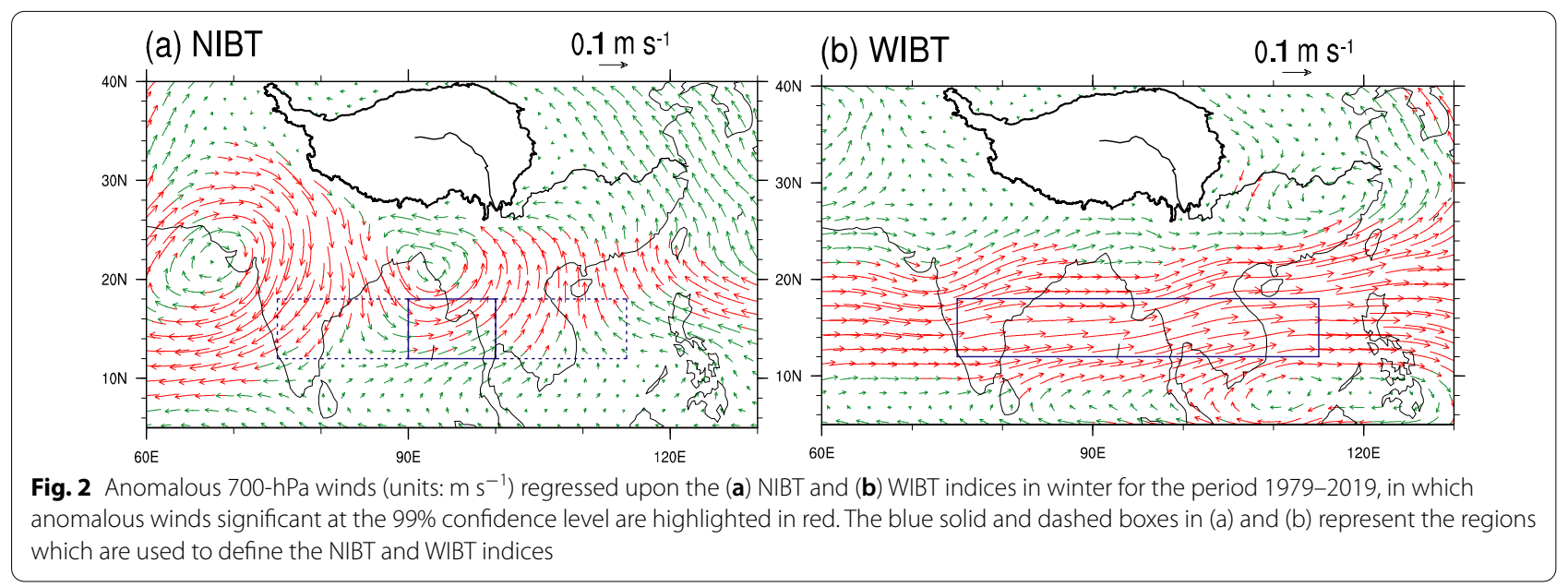


index visually reflects a circulation shape that looks like a WIBT from the BoB to southern China (Fig. 2b; hereinafter call the WIBT-like circulation), which should be considered as a mixed circulation of the westerly and the IBT.

To compare the NIBT/WIBT index with the traditional vorticity-based IBT index, we presented the vorticity anomalies regressed upon the NIBT (Fig. 3a) and WIBT indices (Fig. 3b). Corresponding to a higher NIBT index, a significant positive anomaly appears around the $\mathrm{BoB}$ and the Indochina continent (Fig. 3a). The region of significant positive anomaly agrees well with the key region $\left(15-25^{\circ} \mathrm{N}, 80-100^{\circ} \mathrm{E}\right)$ that is used to define the traditional vorticity-based IBT index (Wang et al. 2011; $\mathrm{Lu}$ and Ren 2016). The correlation coefficient between the NIBT and vorticity-based indices is 0.62 , significant at the $99.9 \%$ confidence level. This significant correlation indicates the high consistency between the NIBT and vorticity-based indices.

Corresponding to a higher WIBT index, significant positive vorticity anomalies extend from the Indochina continent to the East China Sea via South China (Fig. 3b). The broader vorticity anomaly seems to reflect a WIBT. However, the significant positive anomalies over South
China and the East China Sea cannot be totally regarded as the result from the WIBT, the westerly-induced water vapor transport may facilitate convection and relevant precipitation (see the following section), which coordinates with the vorticity anomalies over this region. Since the WIBT reflects a mixed circulation of the westerly and the IBT, the large-area significant positive vorticity anomalies seem to be due to the joint contribution of the IBT and westerly anomalies. Note that the key region for defining the traditional vorticity-based IBT index is mainly occupied by normal vorticity (Fig. 3b) and therefore cannot effectively reflect the IBT anomaly. As a result, the traditional vorticity-based IBT index cannot identify the WIBT-like circulation.

In addition, the NIBT and WIBT indices are clearly distinct from the traditional geopotential height-based IBT index, which can be detected in the geopotential height anomalies regressed upon the NIBT and WIBT indices (Fig. $3 \mathrm{c}$ and d). There are no significant anomalies over the $\mathrm{BoB}$ or the Indochina continent (Fig. $3 \mathrm{c}$ and d). As such, the geopotential height-based IBT index correlates weakly with the NIBT/WIBT index, with an insignificant correlation coefficient of $-0.07 /-0.24$. This implies that

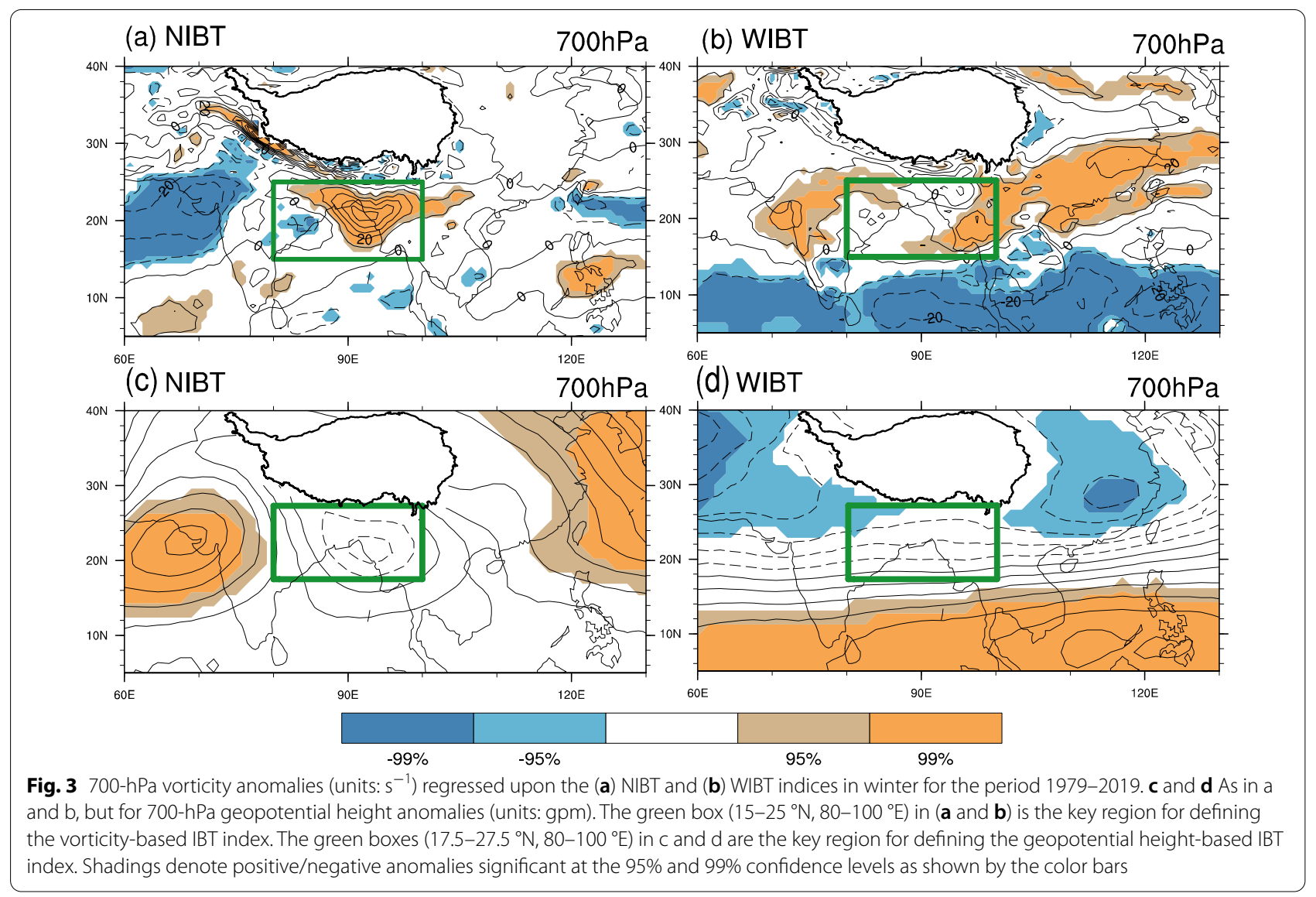


NIBT/WIBT index cannot be replaced with the traditional geopotential height-based IBT index.

In summary, the NIBT and WIBT indices can effectively distinguish the NIBT- and WIBT-like circulation structures, which are different from and cannot be substituted by the traditional vorticity- and geopotential height-based IBT indices.

Note that the WIBT and NIBT indices were calculated from winter mean variable (i.e., winter mean 700$\mathrm{hPa}$ winds). A higher IBT index in a specific year reflects that the troughs occur frequently and prevail over the $\mathrm{BoB}$ during this winter rather than that a trough occurs and then permanently controls the BoB. Therefore, a higher WIBT/NIBT in a specific year can indicate that the WIBT-/NIBT-like circulation is more recurrent during the winter in the year. In a year of both higher WIBT and NIBT indices, both the WIBT- and NIBT-like circulations occur frequently and govern the wind variations alternatively.

\section{Results}

\section{Circulation and precipitation anomalies associated} with the NIBT/WIBT indices

Figure 4 shows the time series of the NIBT and WIBT indices in winter for the period 1979-2019. The variations of the two indices are distinguished from each other, with a very small correlation coefficient of -0.0003 .

Figure 2a presents winter $700-\mathrm{hPa}$ wind anomalies obtained by regression upon simultaneous NIBT index. An anomalous cyclone is observed around the $\mathrm{BoB}$, indicating a stronger NIBT. Corresponding to a stronger NIBT, the northwesterly flow back of the IBT turns northeastward ahead of the IBT. Along the eastern flank of this anomalous cyclone (i.e., ahead of this NIBT), anomalous southwesterlies prevail (Fig. 2a) and induce water vapor transportation from the $\mathrm{BoB}$ to the southeast of the Tibetan Plateau (Fig. 5a). Correspondingly, the water vapor converges around Southwest China (Fig. 5a). Figure 6a shows that the area-mean water vapor divergence averaged over Southwest China $\left(18-28{ }^{\circ} \mathrm{N}\right.$, $100-107^{\circ} \mathrm{E}$; see the black box in Fig. 5 a) is significantly correlated with precipitation over South China (SC) and the middle reaches of the Yangtze River valley (MRYR), around $110^{\circ} \mathrm{E}$. This implies that the convergence of water vapor can facilitate not only local, but also large-area precipitation. Moreover, the precipitation anomaly related to the convergence of water vapor (Fig. 6a) is consistent with that regressed upon the NIBT index (Fig. 5c). Here the NIBT-related precipitation region is called the SC-MRYR region. The results suggest that the stronger NIBT-related southwesterlies and relevant water vapor transport and convergence facilitate precipitation over the SC-MRYR region (Fig. 5c).

Corresponding to a higher WIBT index, winter 700$\mathrm{hPa}$ wind anomalies show the westerly flow from the BoB to the South China Sea and southern China (Fig. 2b). The westerly flow gradually turns northeastward (Fig. 2b), guiding the water vapor transportation to $\mathrm{SC}$ and southeastern China (SEC; Fig. 5b). The water vapor converges from SC to SEC (Fig. 5b), resulting in more precipitation over the SC-SEC region $\left(20-27^{\circ} \mathrm{N}, 105-123^{\circ} \mathrm{E}\right.$; see the black box in Fig. 5d). The correlation between the SC-SEC area-mean water vapor divergence and precipitation further shows their close relationship over the SCSEC region (Fig. 6b). The results reveal that the stronger WIBT-related southwesterly flow and relevant water vapor transport and convergence can supply precipitation over the SC-SEC region. As such, corresponding to a higher WIBT index, more-than-normal precipitation appears over the SC-EC region (Fig. 5d). As mentioned

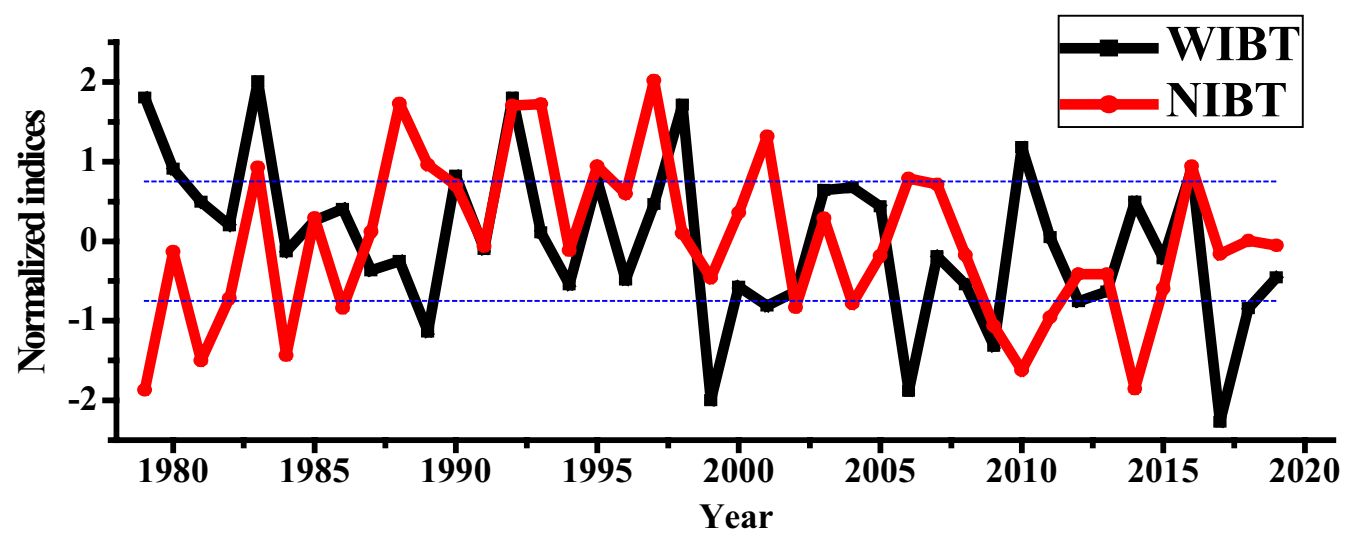

Fig. 4 Time series of the normalized winter (December, January, and February) NIBT (red) and WIBT (black) indices for the period 1979-2019. The blue dashed lines from top to bottom denote +0.75 and -0.75 standard deviations 


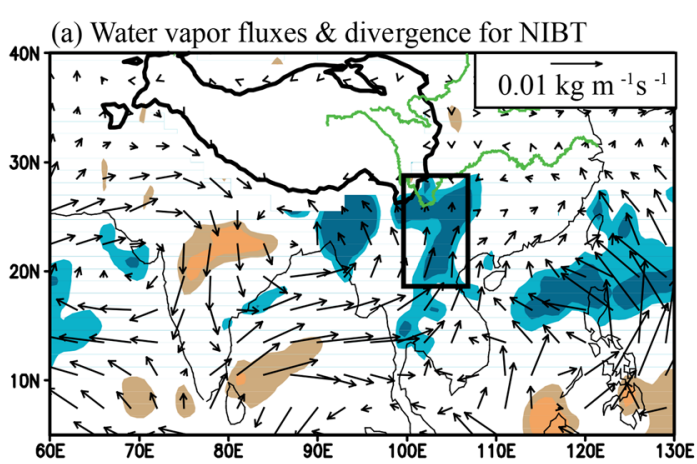

(b) Water vapor fluxes \& divergence for WIBT
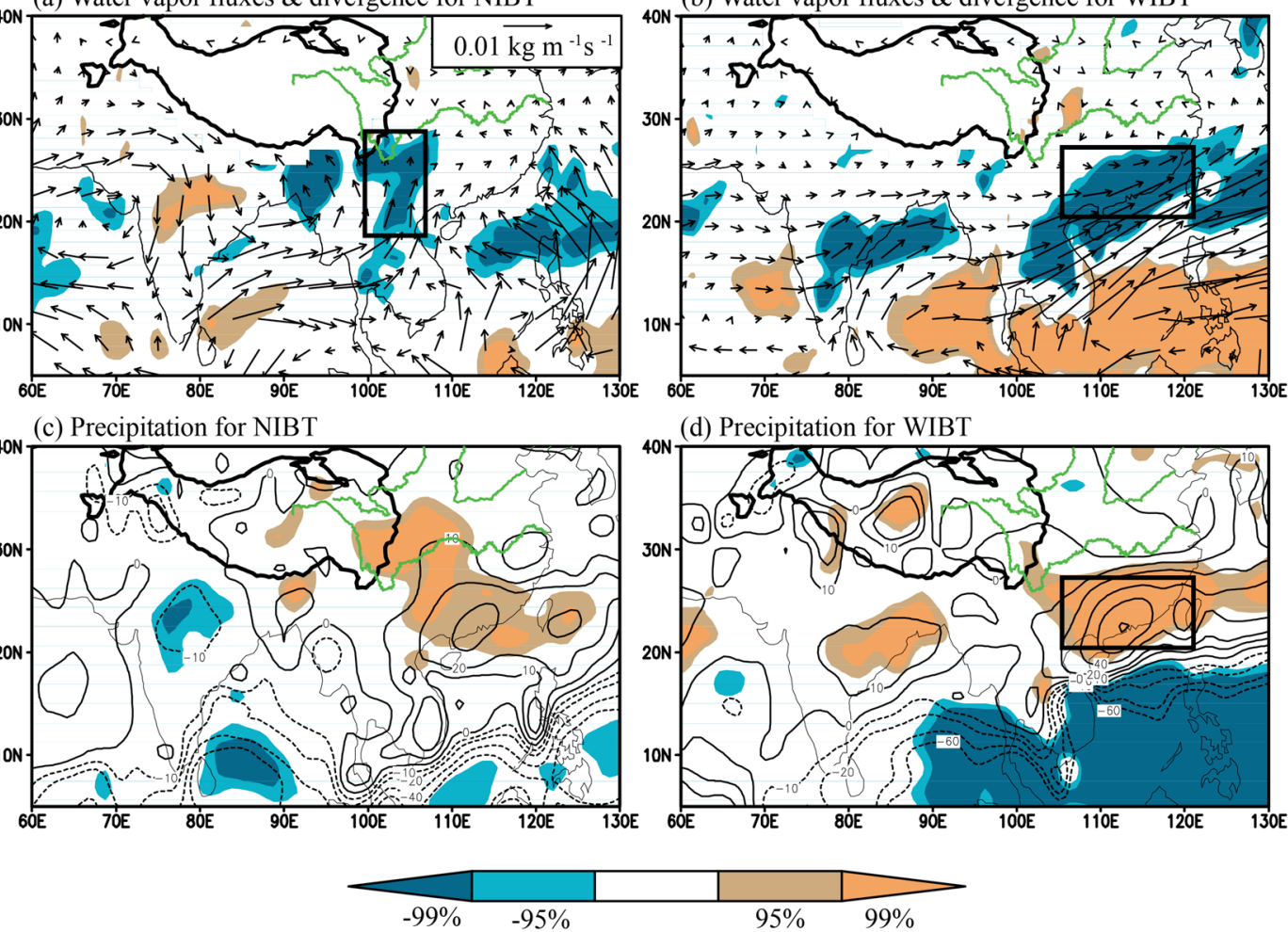

(d) Precipitation for WIBT

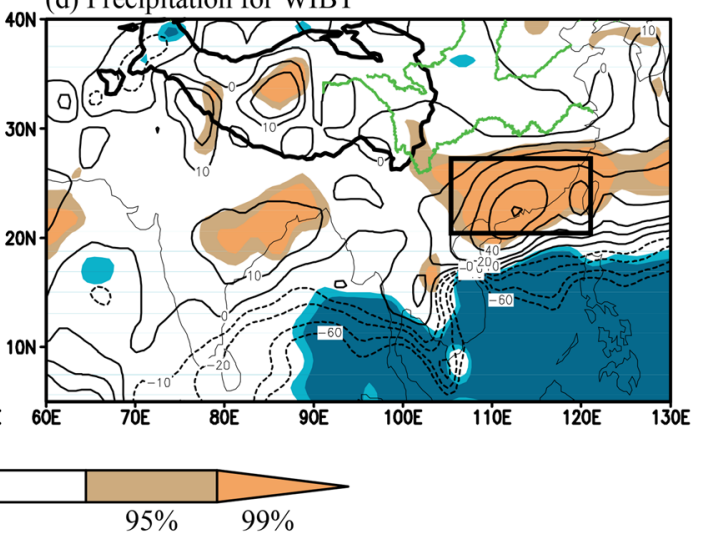

Fig. 5 Anomalous vertical (surface-600 hPa) integral water vapor fluxes (vector, $\mathrm{kg} \mathrm{m}^{-1} \mathrm{~s}^{-1}$ ) and divergence (shading, $10^{-5} \mathrm{~kg} \mathrm{~m}^{-2} \mathrm{~s}^{-1}$ ) regressed upon the (a) NIBT and (b) WIBT indices in winter for the period 1979-2019. (c) and (d) as in (a) and (b), respectively, but for anomalous precipitation (units: $\mathrm{mm}$ ). The black box in (a) denotes Southwest China (SC; $\left.18-28^{\circ} \mathrm{N}, 100-107^{\circ} \mathrm{E}\right)$, and the black box in (b) and (d) denotes the SC-SEC region $\left(20-27^{\circ} \mathrm{N}, 105-123^{\circ} \mathrm{E}\right)$. The two regions are used to calculate the time series of area-mean water vapor divergence in Fig. 6. Shadings denote positive/negative water vapor divergence and precipitation anomalies significant at the $95 \%$ and $99 \%$ confidence levels as shown by the color bars

above, the transportation of water vapor corresponds well to the air flows in front of the NIBT and WIBT. Such a good correspondence implies that the NIBT and WIBT can affect the distribution of precipitation anomalies over southern China through modulating the paths of water vapor transportation.

Note that the NIBT- and WIBT-related precipitation anomalies are not independent from each other, but overlap over the western part of South China. This overlap may be due to that the NIBT- and WIBT-induced paths of water vapor transportation are adjacent to each other. However, the WIBT-related precipitation anomaly around South China is more significant and extends farther eastwards to $122^{\circ} \mathrm{E}$ (Fig. 5d), compared to the NIBT-related precipitation anomaly (Fig. 5c). In short, by modulating the paths of the transportation of water vapor, the NIBT and WIBT induce different distribution of winter precipitation anomalies over southern China even though there is a partial overlap of precipitation anomalies.

We performed similar analyses using the NCEP-NCAR reanalysis-based NIBT/WIBT index and obtained similar results (figure omitted). This further confirms that the NIBT and WIBT indices can be used to describe the NIBT- and WIBT-like circulation and associated precipitation anomalies over southern China during winter.

Based on the time series of WIBT and NIBT indices (Fig. 4), the years of higher NIBT ( $\geq 0.75$ standard deviations; i.e., 1983, 1988, 1989, 1992, 1993, 1995, 1997, 2001, 2006, 2007, and 2016) and WIBT ( $\geq 0.75$ standard deviations; i.e., 1979, 1980, 1983, 1990, 1992, 1995, 1998, 2010, and 2016) indices were selected to perform composite analyses, respectively. Corresponding to the higher NIBT (WIBT) index, the NIBT-like (WIBTlike) circulations appear more frequently than normal and significant positive precipitation anomalies appear around the SC-MRYR (SC-SEC) region (Fig. 7a and b). The composite precipitation anomalies for the years of both higher NIBT and WIBT indices (i.e., 1983, 1992, 1995, and 2016; implying that both NIBTs and WIBTs appear more frequently than normal) show more severe and significant positive precipitation anomalies over the SC, MRYR, and SEC regions (Fig. 7c), covering a larger area than those in the years of the individual 


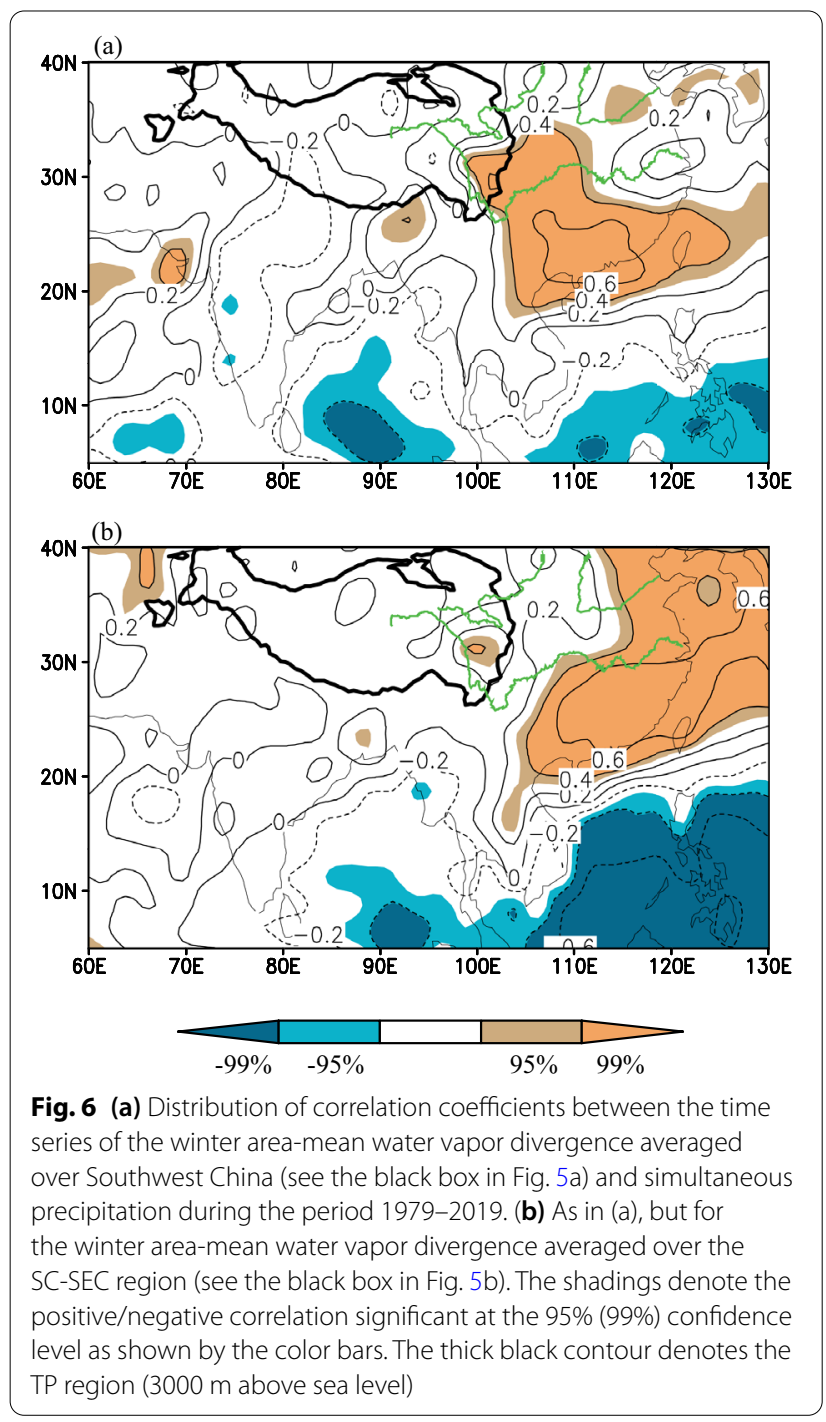

higher NIBT/WIBT index (Fig. 7a and b). The different distribution and severity of precipitation anomalies further reveal that the distinction based on the NIBT and WIBT is meaningful even though the there is an overlap of precipitation anomalies over South China.

We further explore whether a higher criterion $(0.90$ standard deviation) can affect the result of composite analyses. Using the criterion of 0.90 standard deviation, the composite winter precipitation anomalies (figure omitted) are basically consistent with those based on the criterion of 0.75 standard deviation (Fig. 7a, b and c). The consistency implies that the higher criterion does not affect the result. We did not choose a higher criterion, for instance, 1.0 standard deviation as that reduces the sample number, especially for the years of both higher NIBT and WIBT indices (only 1992 above 1.0 standard deviation). The above composite analyses are based on station-observed precipitation. We also repeated these composite analyses using the CMAP dataset and obtained consistent results (figure omitted).

However, in the years of the lower NIBT/WIBT index $(\leq-0.75$ standard deviations), there are no largearea significant anomalies of winter precipitation over southern China (Fig. $7 \mathrm{~d}-\mathrm{f}$ ). These composite analyses imply asymmetric effects of stronger and weaker NIBT/ WIBT on winter precipitation over southern China. The stronger NIBT and WIBT can affect winter precipitation over different regions through modulating the path of transportation of water vapor, whereas the weaker NIBT and WIBT do not seem to play a role in modulating winter precipitation over southern China. When the NIBT/ WIBT is weaker, other factors may play a more important role in modulating winter precipitation over southern China. This deserves further investigation in the future.

\section{Potential factors affecting NIBT and WIBT}

Further analyses show that different factors govern the variabilities of the NIBT and WIBT, respectively. The variability of the NIBT is closely linked with and seems to be modulated by a wave train from the Mediterranean Sea to the BoB. Winter 200-hPa geopotential height anomalies regressed upon the simultaneous NIBT index clearly show a positive-negative alternating wave train from the Mediterranean Sea to the BoB via the Arabian Peninsula and northern Arabian Sea, with a negative anomaly around the BoB and southern China (Fig. 8a). Correspondingly, geopotential height anomalies at 700hPa show a similar wave train pattern, manifesting a quasi-barotropic structure (Fig. 8b). Accompanying the negative geopotential height anomaly at $700-\mathrm{hPa}$ around the BoB, an anomalous cyclone appears in situ (Fig. 8b), showing a NIBT-like circulation. Li and Zhou (2015) suggested that the IBT is part of a wave train from the Mediterranean Sea across the Red Sea and western Arabian Sea to the BoB. Although there is a slight difference in the location of the wave train from Li and Zhou (2015), our result supports that a Rossby wave originating from the Mediterranean Sea can propagate downstream to the $\mathrm{BoB}$, and eventually modulate the variability of the NIBT.

The variability of the WIBT is closely connected with the ENSO during winter, which can be detected in the winter SST anomalies (SSTAs) regressed upon the simultaneous WIBT index (Fig. 9a). Corresponding to a higher WIBT index, warmer SSTs appear in the tropical central and eastern Pacific, while cooler SSTs occur in the tropical western Pacific (Fig. 9a). Since the center of the warmer SSTs is consistent with the Niño 3.4 region, we use the Niño 3.4 index to investigate the contribution of ENSO to the WIBT. Figure $9 \mathrm{~b}$ displays anomalous winter geopotential heights and winds at the $700-\mathrm{hPa}$ level regressed upon simultaneous Niño 3.4 index. The 


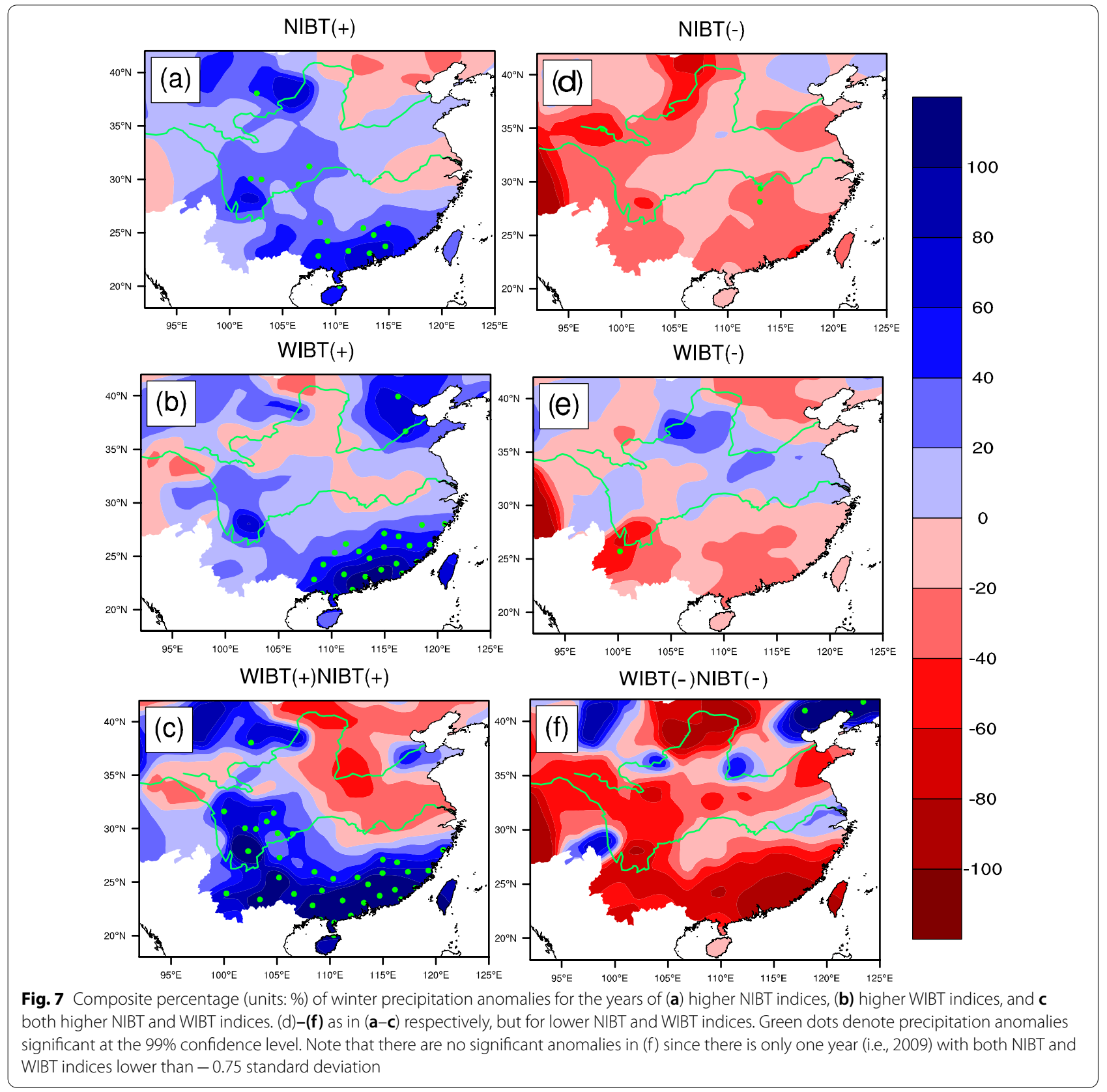

atmospheric circulation pattern shows a typical result of the Matsuno-Gill response (Matsuno 1966; Gill 1980). According to the Matsuno-Gill theory, a lower-tropospheric $(700-\mathrm{hPa})$ anticyclone, as a Rossby wave response to the SST cooling in the tropical western Pacific, appears from the BoB to South China Sea, which is to the northwest of this SST cooling area (Fig. 8b). Along the northern flank of this large anticyclone, anomalous westerly prevails and facilitates a wide extension of the strengthened westerly around the $\mathrm{BoB}$, therefore affecting the WIBT. In contrast, the winter SSTAs regressed upon simultaneous NIBT index reveal that the variability of the NIBT does not connect with the ENSO-like SSTAs (figure omitted). The abovementioned results imply that the ENSO can modulate the WIBT through forcing an anomalous anticyclone around the BoB, but may not affect the NIBT.

\section{Conclusions and discussion Conclusions}

Previous studies show that the distribution of winter precipitation anomalies over southern China is not only 


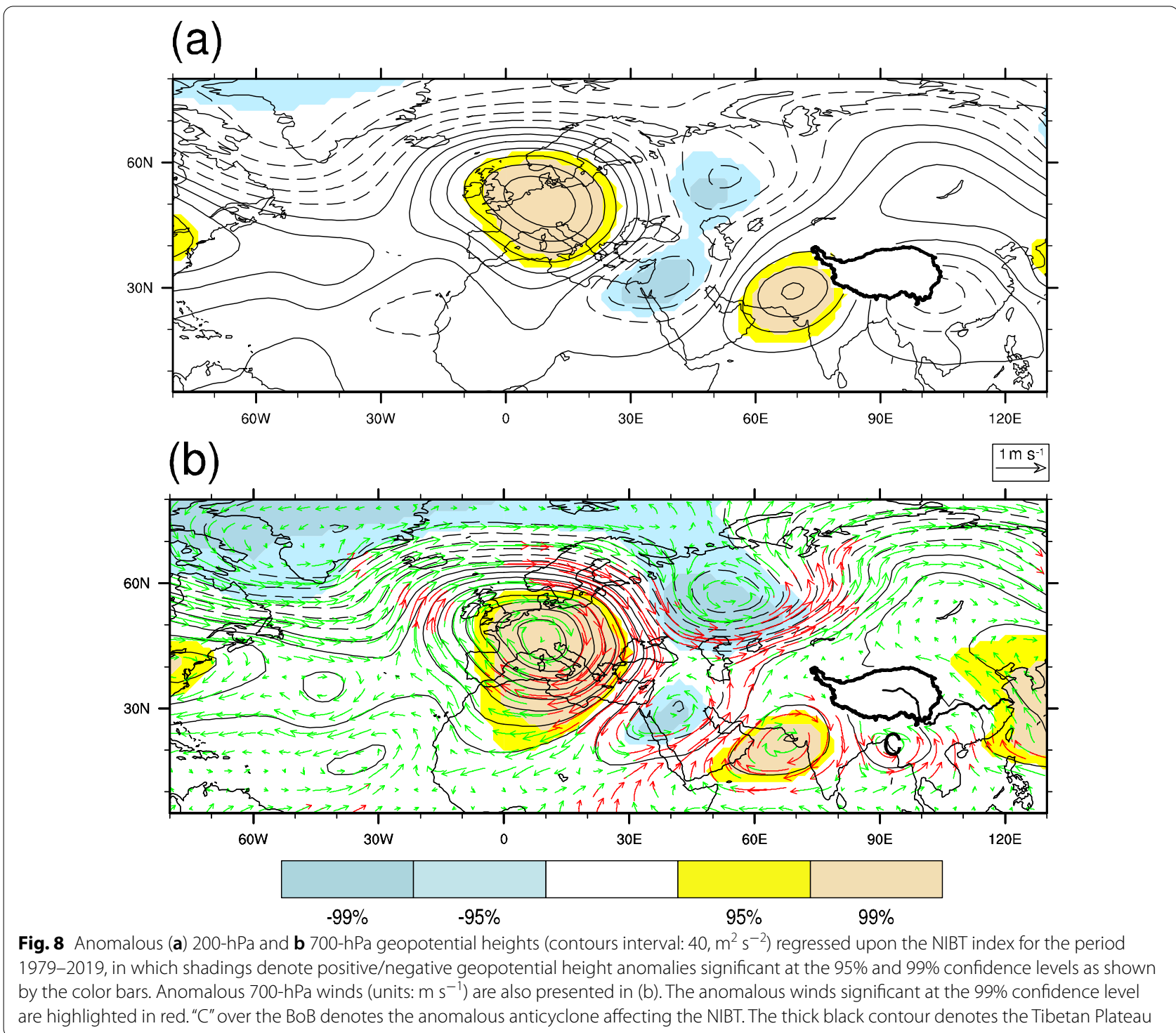

affected by the IBT's intensity, but is also modulated by its shape (i.e., the NIBT- and WIBT-like circulations). By driving the transportation of water vapor in different paths, the wide and narrow IBTs affect the distribution of winter precipitation anomalies over southern China. This situation cannot be described using traditional IBT indices that focus on the intensity of the IBT.

Since there is a close connection between the zonal extending width of the westerly flow along the southern flank of the IBT and the shape of IBT, we defined the WIBT and NIBT indices based on the $700-\mathrm{hPa}$ westerly winds. The NIBT and WIBT indices can effectively distinguish the NIBT- and WIBT-like circulation structures. Corresponding to a higher WIBT index, the westerly and associated water vapor flow from the BoB to southeast China. The relevant water vapor transport and convergence cause winter precipitation anomalies dominantly over southern China (i.e., more precipitation over the SC-SEC region). Corresponding to a higher NIBT index, the westerly flow sharply turns northeastwards ahead of this NIBT and supplies more water vapor to a farther-north location, to the southeast of the Tibetan Plateau. As a result, the relevant water vapor transport and convergence facilitate precipitation over the SC-MRYR region. When the NIBT and WIBT are both stronger, winter precipitation anomalies cover a larger area (i.e., southern China and the MRYR) and are more severe. However, the weaker NIBT and WIBT cannot significantly affect winter precipitation over southern China, signifying the asymmetric effects.

A Rossby wave originating from the Mediterranean Sea can propagate downstream and result in an anomalous 
(a)

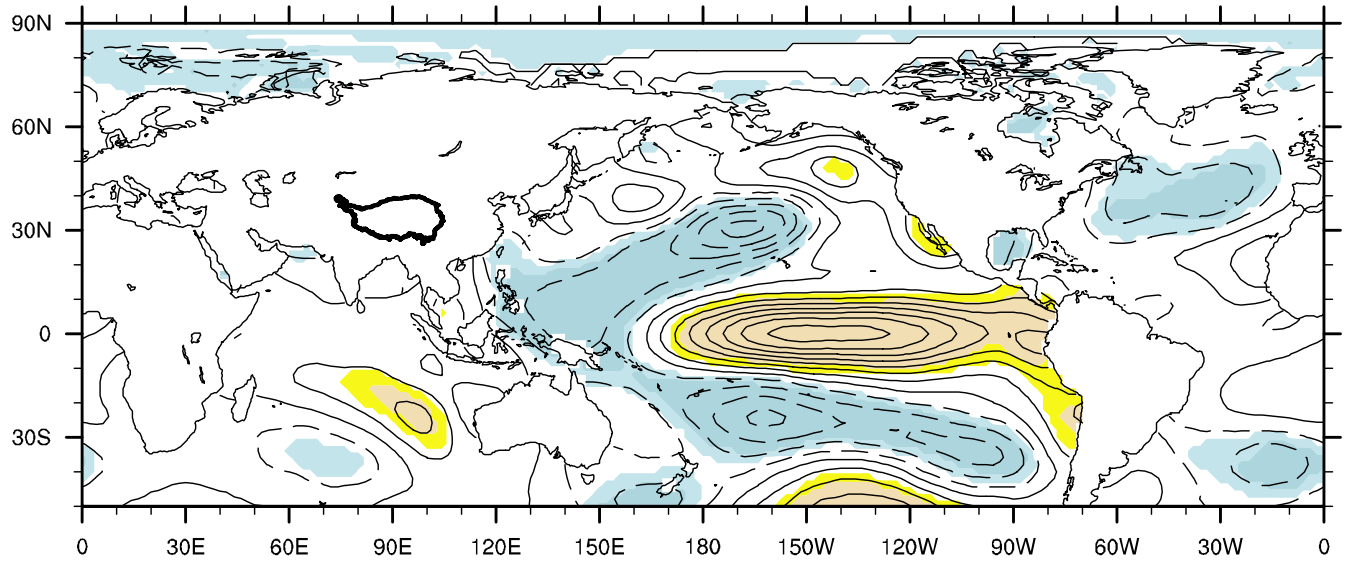

(b) $\stackrel{2 \mathrm{~m} \mathrm{~s}^{-1}}{\longrightarrow}$

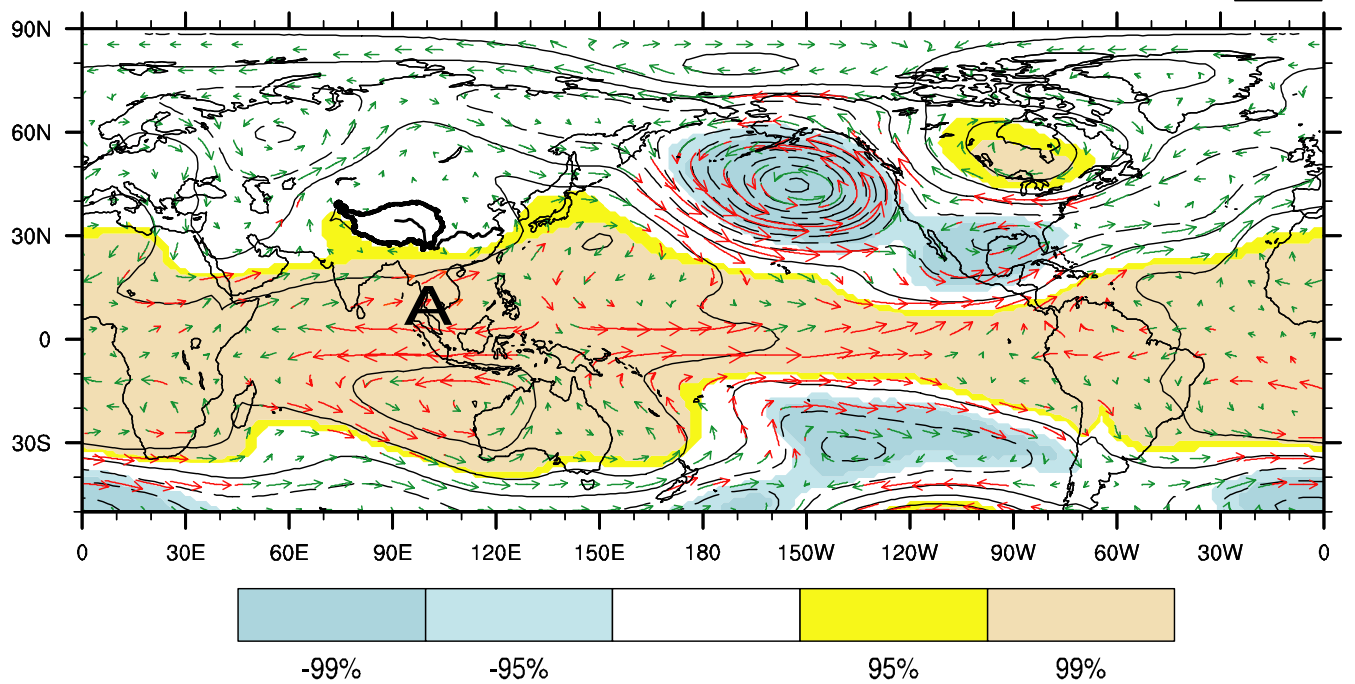

Fig. 9 (a) Winter SSTAs (contours interval: $0.1^{\circ} \mathrm{C}$ ) regressed upon the simultaneous WIBT index. (b) Anomalous 700-hPa geopotential height (contours interval: 40, $\mathrm{m}^{2} \mathrm{~s}^{-2}$ ) and winds (units: $\mathrm{m} \mathrm{s}^{-1}$ ) regressed upon the Niño 3.4 index in winter for the period 1979-2019. Shadings denote positive/negative SSTA anomalies and geopotential height significant at the $95 \%$ and $99 \%$ confidence levels as shown by the color bars. Anomalous winds significant at the $99 \%$ confidence level are highlighted in red. " $\mathrm{A}$ " in (b) denotes the anomalous anticyclone response to the ENSO-related forcing. The thick black contour denotes the Tibetan Plateau

cyclone over the BoB and finally affect the variability of the NIBT. Through exciting the Matsuno-Gill response (Matsuno 1966; Gill 1980), the ENSO can lead to a lowertropospheric large anticyclone from the BoB to South China Sea, which intensifies and extends the westerly flow along the southern flank of the IBT and accordingly modulates the WIBT.

\section{Discussion}

We further compared the precipitation anomalies related to the NIBT/WIBT index with those related to the traditional IBT indices. The vorticity-based IBT index is significantly related to precipitation over the SC-MRYR region during winter (Fig. 10a), which roughly resembles the contribution of the NIBT (Fig. 5c). The geopotential height-based IBT index does not reflect winter precipitation anomalies over southern China well (Fig. 10b). These results imply that some of these traditional IBT indices reflect the effect of the NIBT, but cannot measure that of the WIBT. Recently, Liu et al (2018) defined an IBT index using 700-500-hPa vertical velocity. Evidently, the vertical velocity-based IBT index-related precipitation anomalies (Fig. 10c) are different from the NIBT- and WIBT-related precipitation anomalies (Fig. $5 \mathrm{c}$ and d). 

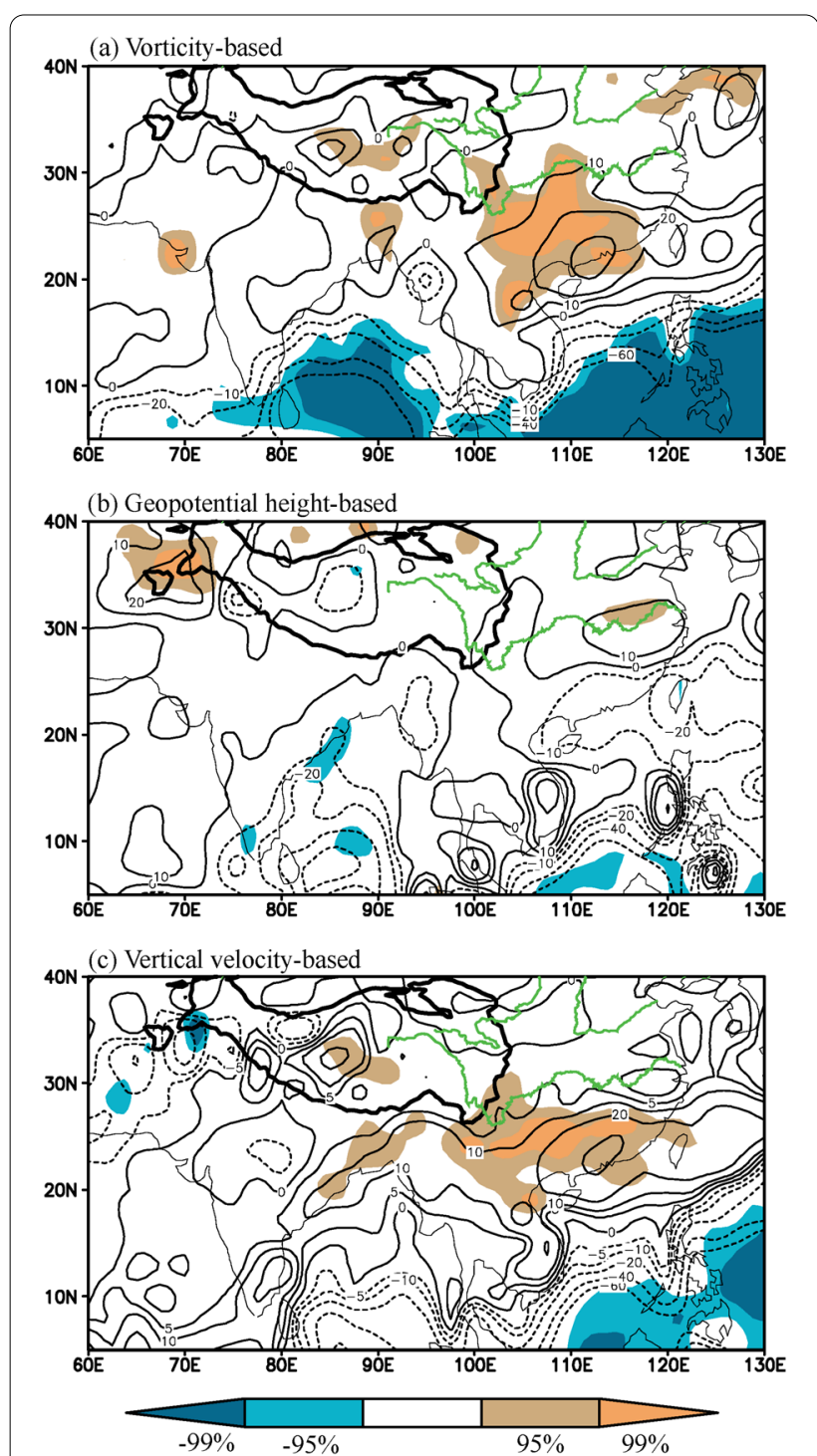

Fig. 10 Anomalous precipitation (units: $\mathrm{mm}$ ) regressed upon the (a) vorticity-based, (b) geopotential height-based, and (c) vertical velocity-based IBT indices in winter for the period 1979-2019. Shadings denote positive/negative precipitation anomalies significant at the $95 \%$ and $99 \%$ confidence levels as shown by the color bars. The vorticity-based IBT index is defined as the area-mean $700-\mathrm{hPa}$ vortices averaged over $\left(15-25^{\circ} \mathrm{N}, 80-100^{\circ} \mathrm{E}\right)$, the geopotential height-based IBT index is defined as the area-mean 700-hPa geopotential height averaged over (17.5-27.5 $\left.{ }^{\circ} \mathrm{N}, 80-100^{\circ} \mathrm{E}\right)$, and the vertical velocity-based IBT index is defined as the area-mean $700-500-\mathrm{hPa}$ vertical velocity averaged over $\left(15.625-24.375^{\circ} \mathrm{N}\right.$, 90.625-100.625 $\left.{ }^{\circ} \mathrm{E}\right)$. The thick black contour denotes the Tibetan Plateau

The vertical velocity-based IBT index generally captures winter precipitation anomalies over southern China, tending to mix the NIBT- and WIBT-related precipitation anomalies. Therefore, the WIBT and NIBT indices are important supplements to these traditional IBT indices.

Additionally, the distribution of winter precipitation anomalies associated with the NIBT index is distinct from that associated with the traditional IBT indices, especially in a large domain, although the NIBT index is significantly correlated with the vorticity-based IBT index. The NIBT-related precipitation anomalies show an out-of-phase variation between the central Indian subcontinent and the region from the south margin of the Tibetan Plateau to southwest China (Fig. 5c), clearly different from that related to the traditional IBT indices (Fig. 10). The WIBT-related precipitation anomalies show an in-phase variation between the northeastern Indian subcontinent and southeast China (Fig. 5d), which is also distinct from Fig. 10. These results further support the necessity of the new IBT indices and suggest that the effect of the NIBT/WIBT on winter precipitation over the larger domain requires further investigation in the future.

Moreover, the mechanisms of changes in the shape of IBT deserve further investigation. For example, the winter SSTAs regressed upon simultaneous NIBT index show significant negative SSTAs in the tropical and highlatitude North Atlantic (figure omitted). However, the interactions among the North Atlantic SSTAs, the wave train from the Mediterranean Sea to the BoB, and the NIBT are complex, and thus we cannot simply attribute the variability of the NIBT to the SSTAs in the North Atlantic. It is worth exploring whether the North Atlantic SSTAs are responsible for, to some extent, the variability of the NIBT in the future. Nevertheless, the present study has revealed that the mechanisms of changes in the shape of IBT are noticeably different from each other. The different distribution of winter precipitation anomalies may be predicted through forecasting the NIBT and WIBT indices using different signals. This can also be regarded as an important implication of the new indices.

\section{Acknowledgements \\ We thank the two reviewers who provided constructive comments. This work was jointly sponsored by the National Key Research and Development Progarm on Monitoring, Early Warning and Prevention of Major Natural Disaster (2018YFC1506001), the Second Tibetan Plateau Scientific Expedition and Research (STEP) Program (2019QZKK0105), the Strategic Priority Research Program of the Chinese Academy of Sciences (XDA20100300), the National Key Research and Development Program on Monitoring (2018YFC1505700, 2018YFC1507700), the National Natural Science Foundation of China (91937301) and the Basic Research Fund of CAMS (2021Z007, 2020Z003, 2019Z008).}

\section{Authors' contributions}

$J$-XL contributed to data analyses and wrote the manuscript; GL defined the wide and narrow IBT indices and wrote the manuscript; RW participated in constructive discussion and revised the manuscript; H-LR contributed to part of the conception of the study; H-MW, XM and X-CW participated in part of analyses and revision. 


\section{Availability of data and materials}

Climate Prediction Center (CPC) Merged Analysis of Prediction (CMAP) can be accessed at https://psl.noaa.gov/data/gridded/data.cmap.html. European Centre for Medium-Range Weather Forecasts (ECMWF) can be accessed at https://apps.ecmwf.int/datasets/data/interim-full-moda/levtype=pl/. National Center for Environmental Protection-National Center for Atmospheric Research (NCEP-NCAR) Reanalysis Project can be accessed at https://psl.noaa. gov/data/gridded/data.ncep.reanalysis.pressure.html. National Oceanic and Atmospheric Administration (NOAA) extended reconstructed SST version 4 can be accessed at https://psl.noaa.gov/data/gridded/data.noaa.ersst.v4. html. Niño 3.4 index can be obtained at https://psl.noaa.gov/data/correlation/ nina34.anom.data. National Meteorological Information Center (NMIC) can be accessed at http://10.1.64.154/

\section{Declarations}

\section{Competing interests}

The authors declare no competing financial interests.

\section{Author details}

${ }^{1}$ State Key Laboratory of Severe Weather, Chinese Academy of Meteorological Sciences, 46 Zhong-Guan-Cun South Avenue, Beijing 100081, China. ${ }^{2} \mathrm{Col}-$ laborative Innovation Centre On Forecast and Evaluation of Meteorological Disasters, Nanjing University of Information Science and Technology, Nanjing, China. ${ }^{3}$ Department of Atmospheric Sciences, School of Earth Sciences, Zhejiang University, Hangzhou, China.

Received: 29 July 2021 Accepted: 20 January 2022 Published online: 07 February 2022

\section{References}

Dao S (1953) The influence of the trough from Indo-Burma on the Weather of Southern China in winter. Acta Meteor Sin 01:40-60

Dee DP, Uppala SM, Simmons AJ, Berrisford P, Poli P, Kobayashi S, Andrae U, Balmaseda MA, Balsamo G, Bauer P, Bechtold P, Beljaars ACM, van de Berg L, Bidlot J, Bormann N, Delsol C, Dragani R, Fuentes M, Geer AJ, Haimberger L, Healy SB, Hersbach H, Holm EV, Isaksen L, Kallberg P, Koehler M, Matricardi M, McNally AP, Monge-Sanz BM, Morcrette JJ, Park BK, Peubey C, De Rosnay P, Tavolato C, Thepaut JN, Vitart F (2011) The ERA-Interim reanalysis: configuration and performance of the data assimilation system. Q J R Meteorol Soc 137(656):553-597

Duan X, Tao Y, Xu ML, Lu Y, Liang H (2012) Influence of south branch trough of westerlies on weather of Yunnan province. Plateau Meteor 31(4):1059-1065

Gill AE (1980) Some simple solutions for heat-induced tropical circulation. Quart J Roy Meteor Soc 106:447-462

Hu M, Gong D, Wang L, Zhou T, Zhang Z (2012) Possible influence of JanuaryMarch Arctic Oscillation on the convection of tropical North Pacific and North Atlantic. Acta Meteorol Sin 70(3):479-491 (In Chinese)

Huang B, Banzon VF, Freeman E, Lawrimore J, Liu W, Peterson TC, Smith TM, Peter TW, Woodruff SD, Zhang HM (2015) Extended reconstructed sea surface temperature version 4 (ERSSTV4). Part I: upgrades and intercomparisons. J Clim. 28(3):911-930

Jia X, Chen L, Ren F, Li C (2011) Impacts of the MJO on winter rainfall and circulation in China. Adv Atmos Sci 28(3):521-533

Kalnay E, Coauthors (1996) The NCEP/NCAR 40-year reanalysis project. Bull Amer Meteor Soc. 77, 437-441

Li C, Sun J (2015) Role of the subtropical westerly jet waveguide in a southern China heavy rainstorm in December. Adv Atmos Sci 32(5):601-612

Li XZ, Zhou W (2015) Modulation of the interannual variation of the IndiaBurma Trough on the winter moisture supply over Southwest China. Clim Dyn 46(1-2):147-158

Li D, He J, Tang X, Lei X, Hou Y (2007) Relationship between the intensity of surface heating over the Qinghai-Xizang Plateau and ENSO cycle. Plateau Meteorol 26:39-46 (in Chinese)

Li X, Chen YD, Zhou W (2017) Response of winter moisture circulation to the India-Burma trough and its modulation by the South Asian waveguide. J Clim 30(4):1197-1210
Li XZ, Wen ZP, Huang WR (2020) Modulation of south Asian jet wave train on the extreme winter precipitation over southeast China: comparison between 2015/16 and 2018/19. J Climate 33:4065-4081

Liu K, Zhai J, Yang R, Chen J (2018) A new dynamical index for India-Burma trough. Adv Meteorol 2018:1-10

Lü JM, Ju JH, Ren JZh, Gan WW (2012) The influence of the Madden-Julian Oscillation activity anomalies on Yunnan's extreme drought of 20092010. Sci China (earth Sciences) 55(001):98-112

Lu B, Ren HL (2016) SST-forced interdecadal deepening of the winter IndiaBurma trough since the 1950s. J Geophys Res Atmos 121(6):2719-2731

Matsuno T (1966) Quasi-geostrophic motion in the equatorial area. J Meteor Soc Japan 44:25-43

Nan SL, Zhao P (2012) Snowfall over central-eastern China and Asian atmospheric cold source in January. Int J Climatol 32:888-899

Rong Y, Zhang L, Wu F (2020) An investigation of heat source effect of Tibetan Plateau on the wintertime India-Burma Trough. Glob Planetary Change 192(14):103222

Suo MQ, Ding YH (2009) Structures and evolutions of the wintertime southern branch trough in the subtropical westerlies. J Atmos Sci 33:425-442 (in Chinese)

Suo MQ, Ding YH (2014) A case study on the effect of southern branch trough in the subtropical westerlies combined with storm over the Bay of Bengal on Plateau Snowstorm. Meteorol Monthly 40(9):1033-1047 (in Chinese)

Wang B, Wu R, Fu X (2000) Pacific-East Asian teleconnection: how does ENSO affect East Asian climate? J Clim 13(9):1517-1536

Wang T, Yang S, Wen Z, Wu R, Zhao P (2011) Variations of the winter IndiaBurma trough and their links to climate anomalies over southern and eastern Asia. J Geophys Res 116:D23118

Xie P, Arkin PA (1997) Global precipitation: a 17-year monthly analysis based on gauge observations, satellite estimates, and numerical model outputs. Bull Amer Meteor Soc 78:2539-2558

Yang S, Lau K-M, Yoo S-H, Kinter JL, Miyakoda K, Ho C-H (2004) Upstream subtropical signals preceding the Asian summer monsoon circulation. J Clim 17:4213-4229

Yang JC, Tao SY, Yeh TC (1960) Meteorology of the Tibetan Plateau, China Science Press, 280

Yin JH (2005) A consistent poleward shift of the storm tracks in simulations of 21st century climate. Geophys Res Lett 32:L18701

You QL, Kang SC, Ren GY, Fraedrich K, Pepin N, Yan YP, Ma $\sqcup$ (2011) Observed changes in snow depth and number of snow days in the eastern and central Tibetan Plateau. Clim Res 46:171-183

Yue XY, Liu G, Chen JM, Zhou C (2020) Synergistic regulation of the interdecadal variability in summer precipitation over the Tianshan mountains by sea surface temperature anomalies in the high-latitude Northwest Atlantic Ocean and the Mediterranean Sea. Atmos Res 233:104717

Zhang TF, Lu YB, Zhang J, Pu GM, Zhou GL (2007) Contrast analysis of 4 heavy snow events in Yunnan since 2000. J Appl Meteor Sci 18:64-72 (in Chinese)

Zhang YL, Fan GZ, Zhou DW, Xie QX, Zhu LH, Wang BY (2012) The climate characteristics analysis of the wintertime Southern Branch Trough. J Chengdu Univ Inform Technol 27(2):196-201 (in Chinese)

Zong HF, Bueh CL, Wei J, Chen LT (2012) Intensity of the trough over the Bay of Bengal and its impact on the southern China precipitation in winter. Atmos Ocean Sci Lett 5(3):246-251

\section{Publisher's Note}

Springer Nature remains neutral with regard to jurisdictional claims in published maps and institutional affiliations. 